\title{
Regional Integration of Stock Markets in Latin America
}

\author{
Richard Heaney \\ Australian National University \\ Vince Hooper \\ University of South Wales \\ Martin Jaugietis \\ Towers Perrin
}

\begin{abstract}
This paper examines the trend towards regionalism upon stock market returns in Latin America. Average correlations with other countries in the region and with the world suggest that the Latin American stock markets have become more regionally integrated over the study period. This finding reflects the growing cooperation between Latin American countries since liberalisation in the early 1990s. Prior to liberalisation, Latin American stock market returns showed greater association with the more developed markets, particularly the USA, than with their closest neighbour. This may have been due to the high dependence upon debt from these developed countries. Analysis highlights the importance of stock market data in helping researchers understand and monitor the regional integration process in Latin America.

- JEL Classifications: F15, F36, G12, G15

- Key Words: Regionalism, Time Changing Correlations, Integration

*Corresponding address: Richard Heaney, Reader, School of Finance and Applied Statistics, Faculty of Economics and Commerce, ANU, Canberra. Australia, Tel: +61-2-6125-4508, Fax: +61-2-6125-0087, E-mail: Richard.Heaney@anu.edu.au

Vince Hooper, Senior Lecturer, School of Banking and Finance, University of New South Wales, Sydney, Australia, Tel: +61-2-9385-5984, Fax: +61-2-9385-6347, E-mail: V.Hooper@unsw.edu.au Martin Jaugietis, Latin American Markets Analyst, Towers Perrin, Melbourne, Australia (C2002-Center for International Economics, Sejong Institution, All Rights Reserved.
\end{abstract}




\section{Introduction}

There has been a trend towards the concept of regionalism as a mechanism for promoting world trade. It may be argued that it is more cost effective and beneficial to negotiate trade on a regional rather than on a multilateral basis because there are a lesser number of participants in the game for liberalisation (Cochinard, 1995). Further, similar legal, economic, geographic and cultural factors make regionalism more conducive to trade. Regionalism has thus reinforced the multilateral mechanism by which international trade is conducted. With trade and other factors ultimately being reflected in corporate profit, it is expected that equity returns will provide an important indicator of changes in the level of economic integration. As a result, in this paper we examine the impact of regionalism upon stock market returns in Latin America.

Within Latin America there has been a shift towards regionalism from the doctrine of multilateralism (Tussie, 1998). Historically, multilateralism has been a more effective integrative economic strategy for Latin America than regionalism. Recent evidence of this phenomenon can be observed during the debt crisis that affected Latin American countries during the 1980s. ${ }^{1}$ Indeed, in 1980, 24.1\% of exports from countries in the Central American Common Market were intraregional; by 1990 this proportion had fallen to $14.8 \%$ (de la Torre and Kelly, 1992). However, the 1990s was a period characterised by greater regional integration in Latin America. Although Mexico and Chile continue to have stronger links with the United States than the region, the other emerging markets have joined neighbouring nations in trade groupings. Bolivia, Colombia, Ecuador, Peru and Venezuela belong to the Andean group, while Argentina, Brazil, Paraguay and Uruguay belong to the Mercosur group. Tracing the history of these groups more closely, the Andean group had in the 1970s been distinctly antagonistic towards the concept of increased opening up of its markets. Yet, initiatives that took place in the early 1990s reduced domestic intervention in foreign trade, laid the foundations of a common external tariff, and established a free trade zone. Intra-regional trade had grown by an estimated $83 \%$ since 1970 to 1992, and was further enhanced by an agreement to establish free trade between Colombia and Venezuela with Central America in 1994 (Gwynne, 1994). The

\footnotetext{
${ }^{1}$ Gwynne (1994) finds that individual countries attempted to foster trade links with the United States, the European Community and Japan. Governments relaxed restrictions on foreign investors from developed nations, while intra-regional linkages became a secondary priority.
} 
Mercosur group, established in March 1991 by the Treaty of Asuncion, has experienced by far the quickest rate of intra-regional expansion in Latin America with 40\% growth in trade between 1991 and 1992, totalling \$7.1 billion. This group's main markets, Brazil and Argentina, though growing rapidly themselves, were however, characterised by differing macro-economic conditions - hyperinflation and a devalued currency in Brazil, and fixed, overvalued exchange rates in Argentina (Nofal, 1995).

Regionalism may be defined as an attempt to promote the theory of free trade and economic development on a geographical basis.

"Economic development is inherently endowed with a spatial dimension, which derives from the important cumulative effects of synergy and feedback which are activated by spatial proximity..."

Pompili (1994)

Regional integration has both economic and political connotations. It is not necessarily just an economic union. Rather, regionalism involves the elimination of various forms of disagreement and discrimination between participating countries (Balassa, 1982). Agreements range from the removal of internal tariffs and quotas to the total unification of political and super-national institutions. Nationalistic tendencies may prevent the loosening of trade barriers because of a country's desire to maintain their own political sovereignty. In developing markets, there is a perception that developed countries close off their markets to the exports from developing countries while still wanting to establish their own markets in developing countries. Further, the regionalism trend appears strong and it is possible that a shift in world trade patterns may cause the emergence of three distinct and separate trading blocs centred on the European Union, the Americas, and Asia (Kim, 1992). The acceleration of international economic interdependence during the 1970s and 1980s is not a phenomenon solely characteristic of industrialised nations:

"Globalisation of economic activity is evident not only in industrialised regions but also in less developed countries".

Michalak (1994)

Multinational enterprises have been instrumental in the development of capital markets in Latin America and have increased the stock of foreign direct investment in Latin America. Multinationals have become so powerful that they transcend national governments in their influence, and are the prime force behind the liberalisation of trade and the deregulation of national economies. ${ }^{2}$ For 
example, many multinationals organise their global activities around the existence of regions (Vernon, 1996).

Argentina provides a useful case study of change in Latin American countries in the 1980s and 1990s. Our analysis focuses on Argentina, Brazil, Chile, Columbia, Mexico and Venezuela. As Brazil, Chile, Colombia, Mexico and Venezuela have followed a similar economic and political trajectory as Argentina the following discussion emphasises the changes in Argentina. Throughout the 1980s, Argentina encountered numerous financial crises. Argentina faced many problems associated with its exchange rate and low credit rating. The Argentine invasion of the Falkland Islands was viewed as a diversion away from many of the economic problems that it was experiencing in the 1980s. In 1985 there was a severe banking crisis that precipitated the debt crisis. Western banks had lent heavily to the developing countries and were penalised, having to write-off many of their outstanding loans. There was a dramatic shift in the economic policies of Argentina from 1989 onwards with a movement towards more free market orientated policies. The official exchange rate was abolished and capital was allowed to flow more freely. Restrictions on foreign investment were also lifted. Portfolio flows of equity were harnessed since the loans from Western Banks were in short supply following the debt crises in the late 1980s. During the 1990s the government embarked upon a programme of privatisation of former inefficient state-run industries. This increased the demand for equity as a source of finance. Equity markets in Latin America have been traditionally thin and foreign investment in the newly privatised companies was encouraged. The economic liberalisation and labour market reforms have continued in Argentina and could even be classified as Thatcherite. ${ }^{3}$ It could be argued that similar changes were observed throughout much of Latin America over this period.

The economic and political events point towards greater liberalisation over time in the Latin-American countries. An interesting phenomenon emerges, that whilst many of the Latin American countries were relatively isolated in terms of trade and investment linkages, they were connected because of their economic dependence upon the Western debt finance. Indeed, as part of the debt relief program, the International Monetary Fund (IMF) stipulated a programme ${ }^{4}$ of economic adjustment that was common to most of the economies in Latin America.

\footnotetext{
${ }^{2}$ A similar argument also presented in Young, Hood and Peters (1994).

${ }^{3}$ A. Gamble. The Free Economy and the Strong State: The Politics of Thatcherism (London, 1994).

${ }^{4}$ These reforms have come to be termed as the Washington Consensus.
} 


\section{Data and Method}

Given that the focus of this paper is on correlations between regional and world equity market returns with Latin American equity market returns, the question of data availability is important. We choose the period from 1985 to 2001 for collection of equity market returns to capture the impact of liberalisation on Latin American equity markets. The choice of this time period restricts the study to just six countries, Argentina, Brazil, Chile, Columbia, Mexico and Venezuela. Monthly total US dollar (USD) returns are used in this study and these are derived using a number of sources, Morgan Stanley Capital International (MSCI) for the world index, Standard \& Poors for the USA index and the International Finance Corporation (IFC) indices for the Latin American country equity market indices. All of these indices are maintained on Datastream. Returns are continuously compounding rates of return adjusted for dividends and capitalisation changes for the period from January 1985 to April 2001. There has been some question of survivorship bias in the IFC indices though Harvey (1995) argues that this is not a serious problem. Further, the use of USDs may be criticised on the grounds that capital controls and restrictions on foreign investment, well known to exist in emerging markets, may reduce the meaningful explanatory power of USD returns. However, evidence suggests that domestic currency returns are similar to those of real currency returns (Richards, 1996), justifying the use of USD returns here. Furthermore, by using USD returns, cross-country comparability is facilitated.

The MSCI international indices provide a broad representation of stocks in different countries. Non-nationals can readily purchase almost all of these stocks. However, criticism has been levelled at MSCI indices because they are weighted towards larger capitalisation stocks. The results are thereby biased towards a somewhat more stable return series characteristic of 'Blue Chip' stocks. The MSCI World index covers $80 \%$ of the world market capitalisation (US\$12.1 trillion) in both developed and emerging markets, and thus provides a reasonably accurate proxy for changes in the value of the world market portfolio. The S\&P 500 composite index is also a broadly based value weighted index focusing on the large USA stocks. It provides an alternative world index as well as allowing for the analysis of changes in correlation between the Latin American equity markets and the USA equity markets.

Latin American Regional correlations are calculated using indices constructed from the IFC indices appearing in the Emerging Markets Data Base (EMDB), 
available on Datastream. The Emerging Markets Data Base includes information on more than 1,800 stocks in low-income and middle-income nations totalling US $\$ 1.2$ trillion in market capitalisation. This represents approximately $10 \%$ of the MSCI world market portfolio. Similar to the MSCI, the IFC uses a subset of stocks in each country based on a target market share of $60 \%$ to $75 \%$ of total market capitalisation. The indices are intended to represent performance measures of the most actively traded stocks across a diversified range of industries. A detailed description of the IFC indices and their construction is contained in "The IFC Indexes" manual (IFC, 1997).

In this study we construct Latin-American regional indices, specific to each country. The use of currently available regional indices, such as the IFC Latin America index, could be criticised when testing the correlation between the regional index returns and equity market returns of a country within the region. This is especially the case for countries with a large market capitalisation. For example, Brazil holds over $40 \%$ of the weight of total Latin American market capitalisation hence with the IFC Latin America index, one would expect that a significant result would be achieved in regressing returns for the larger countries against the regional index by construction. To measure the association between returns in one country and its region, we construct an equally weighted regional index for each country, being based on the remaining countries in the sample. For example, the regional return for Argentina at time $t$ is calculated by averaging the time $t$ returns for the remaining five countries in the sample, Brazil, Chile, Columbia, Mexico and Venezuela. This approach should provide a more accurate assessment of the correlation between country returns and regional returns and reduce the possibility of spurious correlation.

Table 1. Descriptive Statistics for Equity Market Returns

\begin{tabular}{c|cccc}
\hline Country & Mean & Variance & Minimum & Maximum \\
\hline Argentina & 0.0166 & 0.0357 & -1.0485 & 1.0229 \\
Brazil & 0.0082 & 0.0310 & -0.8415 & 0.4228 \\
Chile & 0.0164 & 0.0062 & -0.3091 & 0.1976 \\
Colombia & 0.0107 & 0.0078 & -0.2215 & 0.3173 \\
Mexico & 0.0151 & 0.0189 & -0.8994 & 0.3336 \\
Venezuela & 0.0096 & 0.0191 & -0.6202 & 0.3958 \\
MSCI World Index & 0.0086 & 0.0019 & -0.1859 & 0.1113 \\
S \& P 500 Composite Index & 0.0115 & 0.0020 & -0.2442 & 0.1351 \\
\hline
\end{tabular}

Note: Monthly total return observations $(\mathrm{N}=173)$ are available for Argentina, Brazil, Chile, Columbia, Mexico and Venezuela over the period December 1986 to April 2001. 
Table 2. Correlation Matrix for Equity Market Returns

\begin{tabular}{|c|c|c|c|c|c|c|c|c|}
\hline & Argentina & Brazil & Chile & Colombia & Mexico & Venezuela & $\begin{array}{c}\text { MSCI } \\
\text { Wld }\end{array}$ & $\begin{array}{c}\text { S\&P } \\
500\end{array}$ \\
\hline Argentina & 1.00 & & & & & & & \\
\hline Brazil & 0.58 & 1.00 & & & & & & \\
\hline Chile & 0.62 & 0.62 & 1.00 & & & & & \\
\hline Colombia & 0.27 & 0.33 & 0.37 & 1.00 & & & & \\
\hline Mexico & 0.71 & 0.62 & 0.52 & 0.13 & 1.00 & & & \\
\hline Venezuela & 0.35 & 0.33 & 0.34 & 0.28 & 0.25 & 1.00 & & \\
\hline MSCI Wld & 0.54 & 0.50 & 0.51 & 0.14 & 0.52 & 0.22 & 1.00 & \\
\hline S \& P 500 & 0.43 & 0.40 & 0.40 & 0.12 & 0.40 & 0.13 & 0.89 & 1.00 \\
\hline
\end{tabular}

Note: Monthly total return observations ( $\mathrm{N}=173)$ are available for Argentina, Brazil, Chile, Columbia, Mexico and Venezuela over the period December 1986 to 30 April 2001.

Tables 1 and 2 provide descriptive statistics for the MSCI world index, the S\&P500 Composite index and for the six Latin American equity market return time series used in this study. The average monthly returns (Table 1) range from $0.8 \%$ per month for Brazil to $1.66 \%$ per month for Argentina while the correlations over the total period range from 0.13 for Columbia and Mexico to 0.71 for Argentina and Mexico (Table 2). As might be expected, the correlation between the S\&P500 Composite index returns and the MSCI world returns is relatively high (0.89) for the sample period.

\section{Results and Discussion}

In the following analysis we use rolling 24-month Pearson correlation coefficients to measure the correlation between the chosen Latin American country equity market returns and both the regional and world equity market returns. ${ }^{5}$ Figure 1 represents an attempt to capture the broad impact of time changing correlations between individual country returns and Latin American regional returns and also between individual country returns and world portfolio returns. Correlations between the country returns and the region and between the

\footnotetext{
${ }^{5}$ More complex estimation methods exist for time changing variance and covariance estimates such as multivariate GARCH models though the increased complexity in estimation and loss of degrees of freedom in large multivariate GARCH models precludes their use in this paper. Alternative estimators of co-movement also exist such as the use of Copulas (Rockinger and Jondeau, 2001). Application of these more complex approaches is beyond the scope of this paper and is left to future research.
} 
Figure 1. Average of the Two-Year Rolling Correlations Between the Latin American Countries and their Regional Index and Between the Latin American Countries and the World Indices Over the Period 31 Dec 1986 to 30 Apr 2001

Panel A: Comparison of Regional and World (MSCI) Correlati on Averages

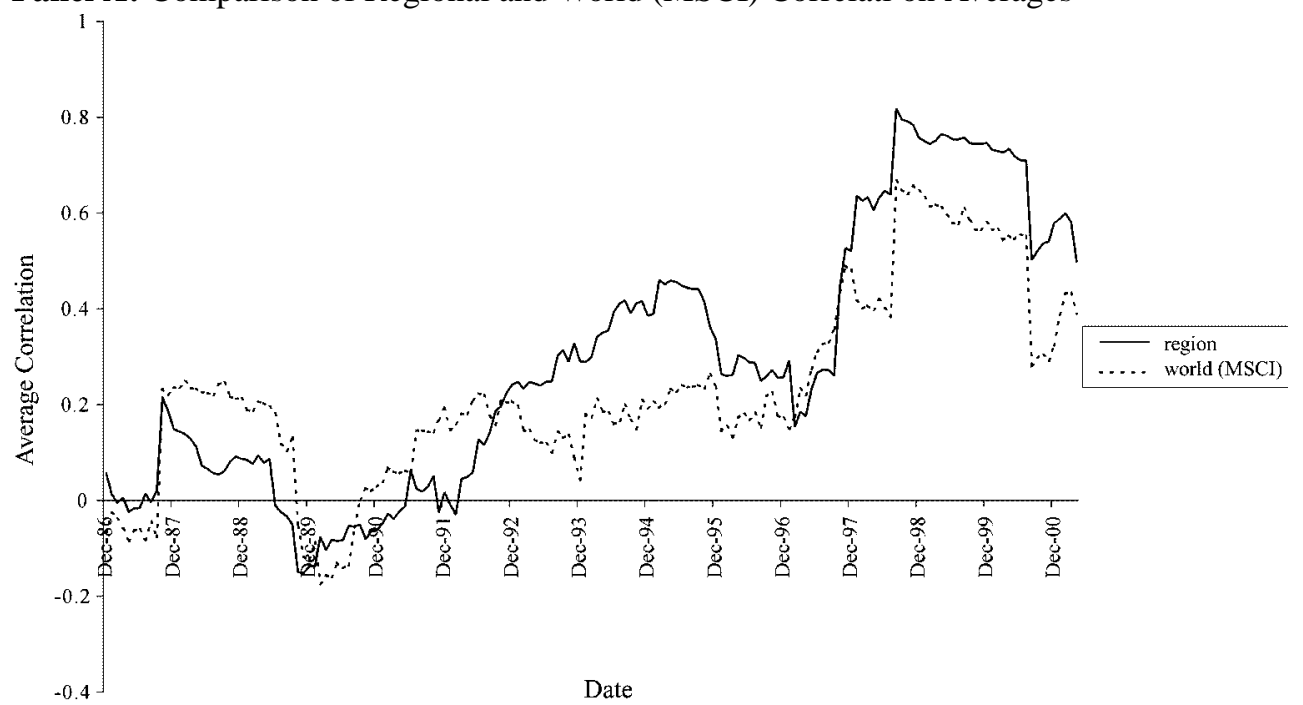

Note: Region is the time series of the average of the two-year rolling correlations between monthly returns for the six countries, Argentina, Brazil, Chile, Columbia, Mexico and Venezuela, and their appropriate regional index. The regional index is constructed by taking the equally weighted portfolio of the available countries in the region, excluding the country of interest. For example the regional return for Argentina at time $t$ is calculated by averaging the returns for the remaining five countries Brazil, Chile, Columbia, Mexico and Venezuela at time $t$. The regional correlation at time $t$ is the correlation between the country returns and the returns on its regional index for the 24 months period ending at time $t$. World (MSCI) is the time series of the average of the two-year rolling correlations between the monthly returns for the six countries, Argentina, Brazil, Chile, Columbia, Mexico and Venezuela, and Morgan Stanley World Index returns.

country returns and the world are calculated using 24 consecutive monthly returns ending at the current month. The regional correlations reflect the correlation between country returns and the returns on the constructed regional index. The world correlations reflect the correlation between the country returns and the proxy for world returns. To identify the general trend in correlation over the study, the correlations are averaged across the available countries each month generating a time series of average correlations, one for the Latin American region and one for the world for each month. These average correlations appear in Figure 1 and the difference between the average of the regional correlations and the average of the world correlations appears in Figure 2.

It is apparent from Figure 1 that the correlation with regional equity markets has become stronger since 1989 with average regional correlations exceeding the 
Figure 1. Average of the Two-Year Rolling Correlations Between the Latin American Countries and their Regional Index and Between the Latin American Countries and the World Indices Over the Period 31 Dec 1986 to 30 Apr 2001

Panel B: Comparison of Regional and World (S\&P500) Correlation Averages.

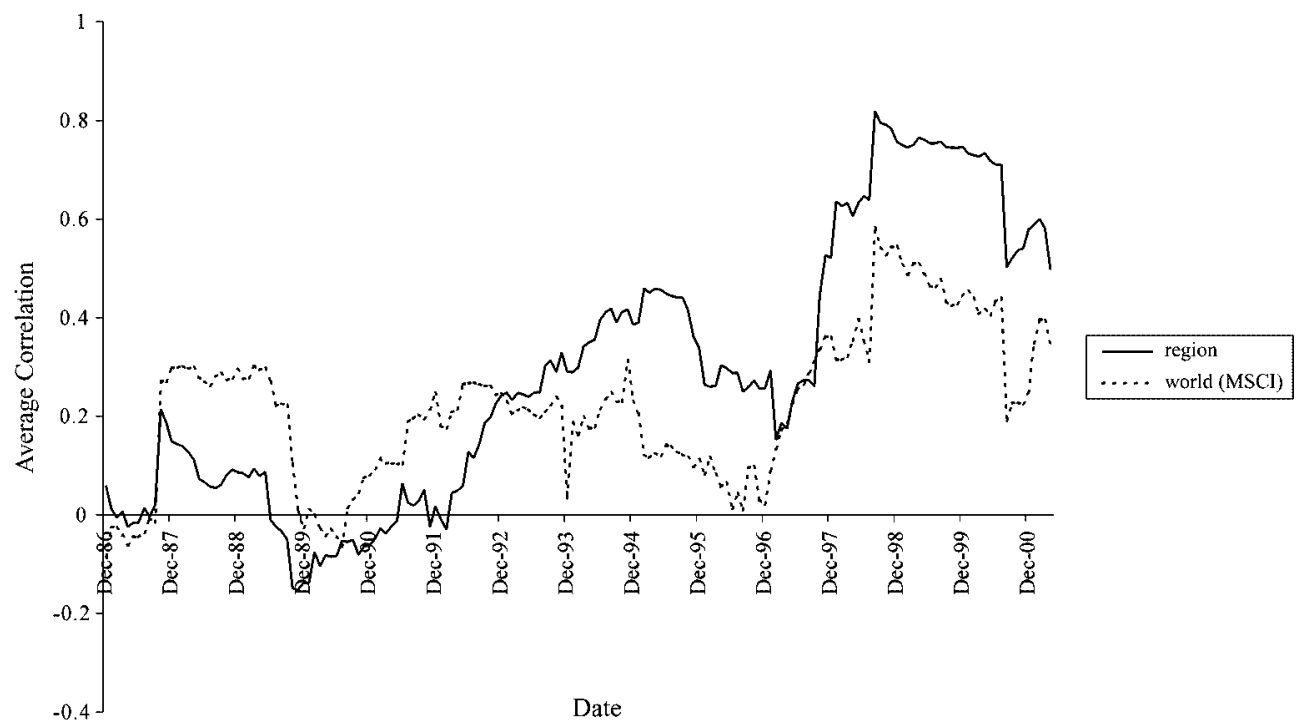

Note: Region is the time series of the average of the two-year rolling correlations between monthly returns for the six countries, Argentina, Brazil, Chile, Columbia, Mexico and Venezuela, and their appropriate regional index. The regional index is constructed by taking the equally weighted portfolio of the available countries in the region excluding the country of interest. For example the regional return for Argentina at time $t$ is calculated by averaging the returns for the remaining five countries Brazil, Chile, Columbia, Mexico and Venezuela at time $t$. The regional correlation at time $t$ is the correlation between the country returns and the returns on its regional index for the 24 months period ending at time $t$. World (S\&P500) is the time series of the average of the two-year rolling correlations between the monthly returns for the six countries, Argentina, Brazil, Chile, Columbia, Mexico and Venezuela, and S\&P500 Composite Index returns.

average world correlations after 1992. This is maintained for most of the post 1992 period except for the 1997 Asia crisis period where a return to the pre 1992 situation of greater world than regional correlation is observed. Prior to the overall liberalisation phase in Latin America, equity markets were more closely correlated with the rest of the world, using either the MSCI or the S\&P 500 Composite index, than regionally with exceptions around the 1987 crash and in the later half of 1990. This effect is particularly evident in Figure 2. The change in relative correlation may be associated with the fact that initially most Latin American countries were indebted to the developed world. Although there was a lack of integration with markets in the 'West', their economies were subject to high exogenous world effects such as changes in the US and UK interest rates, which 
related to high proportions of external debt corresponding with this period. This corroborates studies that have suggested that some emerging markets may appear to be integrated, when in fact they are segmented from one another (Bekaert and Harvey, 1995). The correlation with world markets was higher than regional markets and increasing throughout the late 1980s that coincided with the increasing pressures brought about by the debt crisis of Latin America. Throughout the 1980s regional correlation between the Latin American markets is low when compared to the world correlation. This suggests that exogenous 'shocks' such as the debt crises may actually widen and deepen future economic

Figure 2. Average of the Two-Year Rolling Correlations Between the Latin American Countries and their Regional Index and Between the Latin American Countries and the World Indices Over the Period 31 Dec 1986 to 30 Apr 2001

Panel A: Difference Between Regional and World (MSCI) Correlation Averages

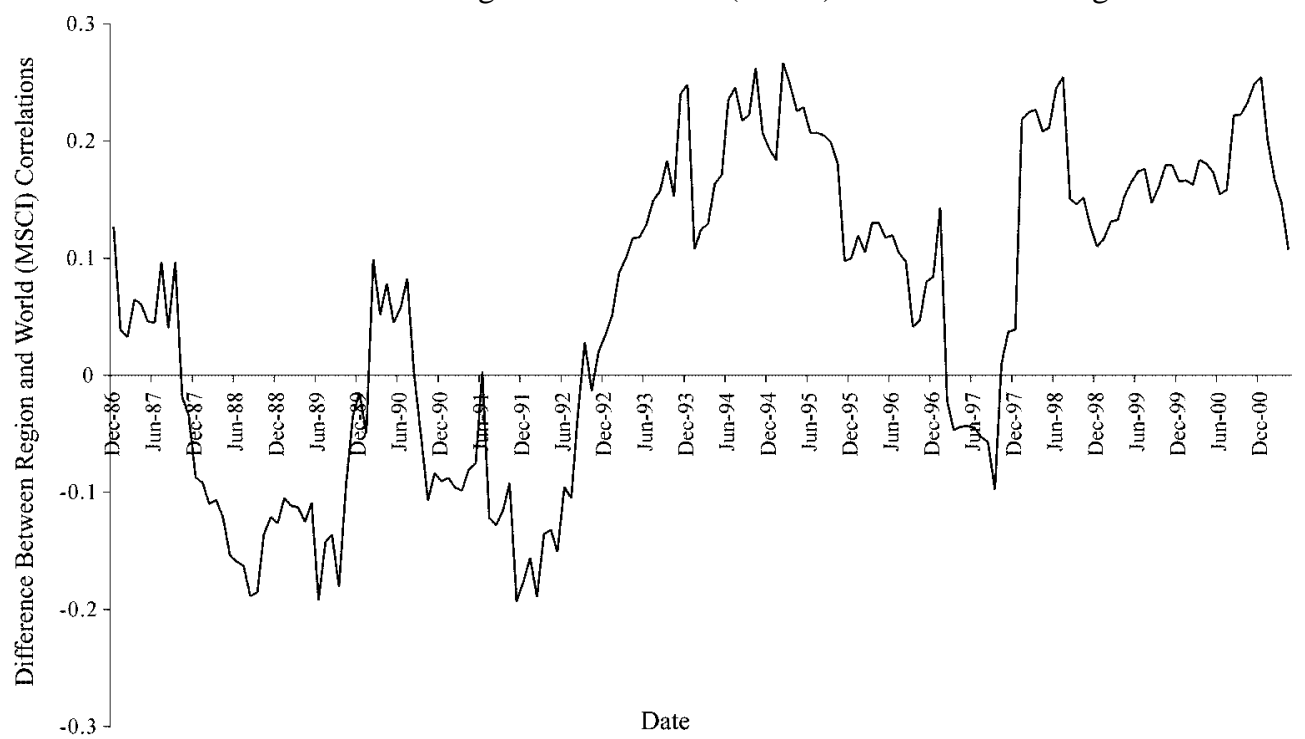

Note: Regional Correlation less World Correlation is the time series of the differences between the average of the correlations with the Region and the average of the correlations with the world for each month. The average of the correlations with the Region refers to the average of the two-year rolling correlations between monthly returns for the six countries, Argentina, Brazil, Chile, Columbia, Mexico and Venezuela, and their appropriate regional index. The regional index is constructed by taking the equally weighted portfolio of the available countries in the region excluding the country of interest. For example the regional return for Argentina at time $t$ is calculated by averaging the returns for the remaining five countries Brazil, Chile, Columbia, Mexico and Venezuela at time $t$. The regional correlation at time $t$ is the correlation between the country returns and the returns on its regional index for the 24 months period ending at time $t$. The average of the correlations with the world (MSCI) is defined as the time series of the average of the two-year rolling correlations between the monthly returns for the six countries, Argentina, Brazil, Chile, Columbia, Mexico and Venezuela, and Morgan Stanley World Index returns. 
Panel B: Difference Between Regional and World (S\&P500) Correlation Averages

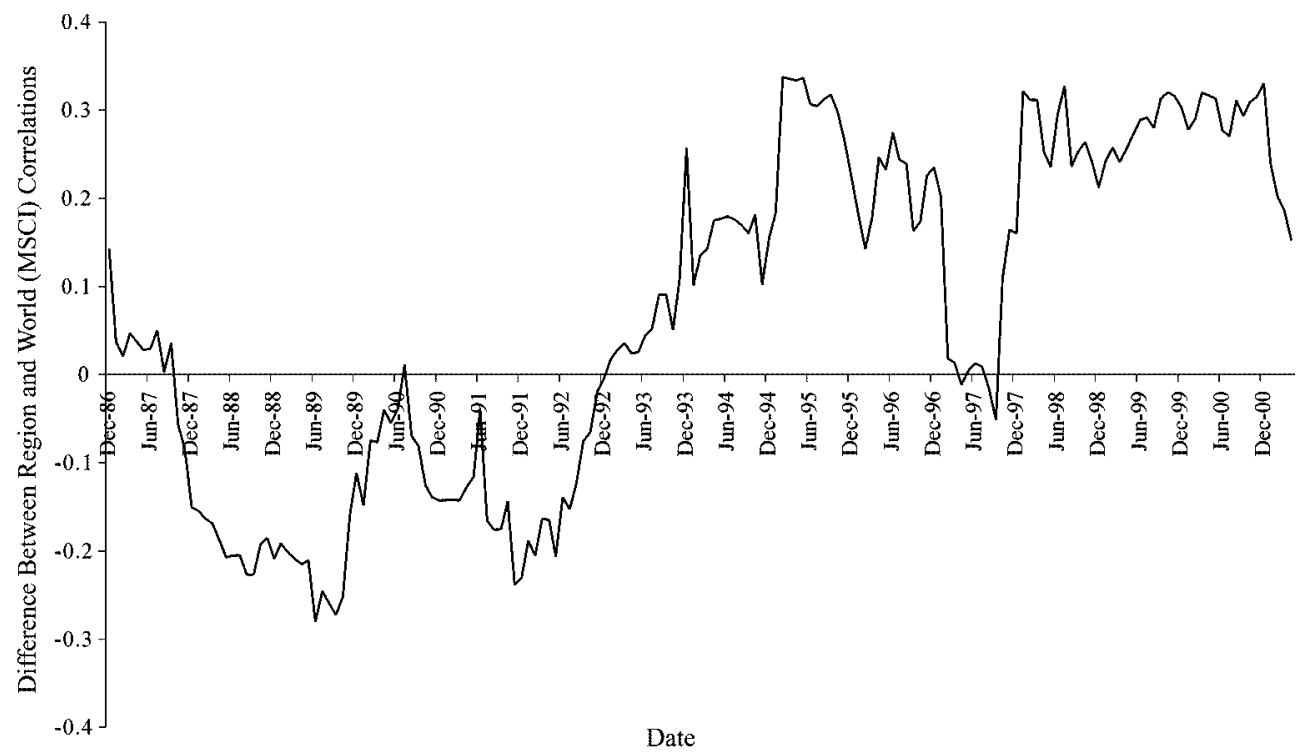

Note: Regional Correlation less World Correlation is the time series of the differences between the average of the correlations with the Region and the average of the correlations with the world for each month. The average of the correlations with the Region refers to the average of the two-year rolling correlations between monthly returns for the six countries, Argentina, Brazil, Chile, Columbia, Mexico and Venezuela, and their appropriate regional index. The regional index is constructed by taking the equally weighted portfolio of the available countries in the region excluding the country of interest. For example the regional return for Argentina at time $t$ is calculated by averaging the returns for the remaining five countries Brazil, Chile, Columbia, Mexico and Venezuela at time $t$. The regional correlation at time $t$ is the correlation between the country returns and the returns on its regional index for the 24 months period ending at time $t$. The average of the correlations with the world (S\&P500) is defined as the time series of the average of the two-year rolling correlations between the monthly returns for the six countries, Argentina, Brazil, Chile, Columbia, Mexico and Venezuela, and S\&P500 Composite index returns.

integration. ${ }^{6}$ Many economies in Latin America experienced strain and stress emanating from the debt crisis and this may have precipitated into greater regional co-operation. Since 1991 (which coincides with the initial phases of financial liberalisation) both regional and global integration have increased dramatically with regional correlation on average greater than world correlation. In addition, there has been a reduction in the level of debt finance and an increase in the reliance on equity capital in Latin America ${ }^{7}$ as a result of the debt crises of the 1980s.

It is interesting to observe (Figure 1, Panels A\&B) that around the global stock

\footnotetext{
${ }^{6}$ This has been suggested in the literature by Baldwin (1997). Idiosyncratic shocks tend deepen or widen regional integration and trigger a multiplier or domino effect producing membership requests from countries that were previously happy to be non-members.

${ }^{7}$ This period of liberalisation has been acknowledged by Kim and Singal (1993) \& Bekaert and Harvey (1995).
} 
market declines that occurred during October 1987 and October $1989^{8}$, the regional correlation of Latin American markets increase and decrease, respectively. There is some literature that suggests that markets become more correlated in times of 'choppy' or volatile markets (Ramchand and Susmel, 1998). However, given the turbulent world financial system around the end of 1987 this did not greatly affect the correlations in Latin American countries as a group because at that time these markets were segmented from the world market portfolio. This is different to the Asian Financial Crisis of 1997 where both regional and world correlations with Latin American countries increase substantially over a short-period of time and remain high throughout 1998, 1999 and 2000, which corresponds with generally higher volatility in emerging stock markets around the globe.

To gain some insight into the variation in time series of rolling correlations that were calculated for each country (Figure 1), regressions are estimated for each of the countries with a dummy variable included to test for a structural change in correlation between two periods. These two periods are December 1986 to December 1990 and January 1991 to April 2001. Given the previous discussion about the impact of the problem loans in the 1980s and the freeing up of the financial systems in Latin America in the 1990s, this choice of break point appears reasonable. The analysis was repeated with the break point at the end of 1992 and the analysis was also run with an additional dummy variable to assess the impact of the 1997 Asian crisis. These changes to the dummy variables in the regressions had little impact on the results and so are not discussed further. The use of rolling correlation estimates induces a high order moving average process into the residuals. Given the asymptotic relationship between moving average and autoregressive processes we choose a low order autoregressive process to capture this effect. A simple AR(1) process is all that is required for most countries to adjust for serial correlation. The regression takes the form:

$$
\operatorname{Diff}_{i t}=\alpha_{1}+\alpha_{2} D_{1991-2001}+\alpha_{3} \operatorname{Diff}_{i t-1}+\varepsilon_{t}
$$

Where Diff ${ }_{i t}$ is equal to the regional correlation less the world correlation for the country, or region, as at time $t$ based on the 24 consecutive returns ending at time $t, D_{1991-2001}$ is the dummy variable used to test for structural change in the correlation estimates with a value of one if the observation time lies between

\footnotetext{
${ }^{8}$ The effect of the sharp falls that occurred in the world stock markets during October 1989 have been incorporated into various studies including Ghosh (1992).
} 
Table 3. Regional Versus World Correlation

\begin{tabular}{l|lllllll}
\hline & Argentina & Brazil & Chile & Mexico & Columbia & Venezuela & Region \\
\hline MSCI & & & & & & & \\
Constant & -0.0075 & -0.0284 & 0.0282 & -0.0214 & -0.0021 & -0.0128 & -0.0088 \\
& $(-0.66)$ & $\left(-2.28^{*}\right)$ & $\left(2.37^{*}\right)$ & $\left(-1.85^{+}\right)$ & $(-0.19)$ & $(-1.25)$ & $(-1.39)$ \\
D1991 & 0.0161 & 0.0394 & -0.0070 & 0.0242 & 0.0196 & 0.0221 & 0.0188 \\
& $(1.19)$ & $\left(2.56^{*}\right)$ & $(-0.54)$ & $\left(1.78^{+}\right)$ & $(1.37)$ & $\left(1.70^{+}\right)$ & $\left(2.24^{*}\right)$ \\
Lag (1) & 0.9157 & 0.9279 & 0.8612 & 0.9001 & 0.8859 & 0.9157 & 0.9142 \\
Rsquare & $\left(31.93^{*}\right)$ & $\left(37.88^{*}\right)$ & $\left(24.29^{*}\right)$ & $\left(31.01^{*}\right)$ & $\left(25.95^{*}\right)$ & $\left(31.62^{*}\right)$ & $\left(32.31^{*}\right)$ \\
F Stat. & 0.86 & 0.93 & 0.78 & 0.86 & 0.82 & 0.89 & 0.90 \\
Chisq(20) & $529.38^{*}$ & $1130.53^{*}$ & $296.85^{*}$ & $500.90^{*}$ & $396.84^{*}$ & $675.33^{*}$ & $745.21^{*}$ \\
S\&P 500 & 19.86 & 20.32 & 29.18 & 19.14 & 21.98 & 15.88 & 25.03 \\
Constant & -0.0205 & -0.0196 & -0.0039 & -0.0306 & -0.0129 & -0.0255 & -0.0133 \\
& $\left(-1.66^{+}\right)$ & $\left(-1.71^{+}\right)$ & $(0.34)$ & $\left(-2.34^{*}\right)$ & $(-1.03)$ & $\left(-2.21^{*}\right)$ & $\left(-1.88^{+}\right)$ \\
D1991 & 0.0327 & 0.0339 & 0.0108 & 0.0410 & 0.0337 & 0.0525 & 0.0241 \\
& $\left(2.15^{*}\right)$ & $\left(2.25^{*}\right)$ & $(0.81)$ & $\left(2.54^{*}\right)$ & $\left(2.02^{*}\right)$ & $\left(3.10^{*}\right)$ & $\left(2.52^{*}\right)$ \\
Lag (1) & 0.9188 & 0.9349 & $1.0452 *$ & 0.9080 & 0.8698 & 0.8816 & 0.9377 \\
Rsquare & $\left(33.70^{*}\right)$ & $\left(38.94^{*}\right)$ & $\left(13.45^{*}\right)$ & $\left(32.47^{*}\right)$ & $\left(23.74^{*}\right)$ & $\left(27.55^{*}\right)$ & $\left(41.83^{*}\right)$ \\
F Stat. & 0.90 & 0.93 & 0.90 & 0.90 & 0.84 & 0.91 & 0.94 \\
Chisq(20) & $687.49^{*}$ & $1197.16^{*}$ & $50.96^{*}$ & $804.77^{*}$ & $446.16^{*}$ & $841.01^{*}$ & $1449.83^{*}$ \\
\hline
\end{tabular}

Note: These regressions focus on the time changing nature of the difference between regional and world correlations for selected Latin American countries. Both the MSCI world index and the S\&P500 composite indices are used to estimate world correlations and equally weighted regional indices are created for estimation of the country correlations. The column titled "region" represents analysis of the average of the individual country correlations with respect to region and world. Tests for structural change in the correlation estimate differences are conducted using an AR(1) model as follows:

$$
\operatorname{Diff}_{i t}=\alpha_{1}+\alpha_{2} D_{1991-2001}+\alpha_{3} \operatorname{Diff}_{i t-1}+\varepsilon_{t}
$$

where Diff $_{\text {it }}$ is the difference between the regional correlation and the world correlation estimates as at time $t$ where these correlation estimates are based on the 24 consecutive monthly returns ending at time t, D1991-2001 is the dummy variable used to test for structural change in the correlation estimates with a value of one if the observation time lies between December 1986 and April 2001 and zero otherwise. The lagged correlation term, Diff $f_{\mathrm{it}-1}$, is included to model serial correlation. The correlations are calculated using the data from 31 January 1985 to 30 April 2001. The first 23 observations are used in calculation of the first correlation coefficient, giving correlations for each month from 31 December 1986 through to 30 April 2001.

+ statistically significant at the $10 \%$ level of significance, *statistically significant at the $5 \%$ level of significance, \# the first of 8 lag terms included to remove serial correlation from the regression residuals.

December 1991 and April 2001 inclusive and zero otherwise. The lagged correlation term, Diff $f_{t-1}$, is included to adjust for serial correlation in the residuals.

The results of the regressions based on equation (1) are reported in Table 3 . The lagged correlation term $\left(\right.$ Diff $\left._{i t-1}\right)$ is statistically significant in all of the regressions 
and the chi-square test for serial correlation in the residuals suggests the choice of an autoregressive process of order one is generally sufficient to capture the impact of induced serial correlation. As apparent in the last column of Table 3 (region), there is evidence of a statistically significant increase in correlation over the study period when using averages across all six countries regardless of the whether the MSCI (Panel A) or S\&P500 (Panel B) index are used for correlation calculation. This is consistent with Figures 1 and 2.

The results from tests for a change in regional/world correlation on a countryby-country basis exhibit some variation according to "world" index choice. When using the broader MSCI index there is limited evidence of a statistically significant change in correlation in a country-by-country analysis over the 1980s and 1990s. Only Brazil exhibits a statistically significant change at the 5\% level, though there is evidence of increasing correlation at the $10 \%$ level of significance for both Mexico and Venezuela. When the S\&P 500 Composite index is used both the regional correlations and five of the six country correlations (with Chile being the exception) exhibit a statistically significant increase in regional correlation relative to correlation with the USA equity market after 1991. Clearly, the level of correlation with the USA has not increased as rapidly as the correlations with the equity markets of the region over the period. These results suggest that Latin American countries exhibit increasing regional and world correlation, though there does not appear to have been the same growth in correlation with the USA equity markets in the 1990s.

Overall, the correlation results provide some confirmation of the argument that a lowering of tariff barriers, financial liberalisation and the inflow of foreign funds leads to increasing correlation between proximate stock markets. Whether regional links have become stronger than world links is not so obvious. There is evidence that, along with a general increase in equity market correlation with both the region and the rest of the world, regional correlation has become stronger than world correlation from 1987 to 2001 . On a country-by-country basis there is some variation in evidence for change in the level of regional correlation relative to world correlation over the study period. The fact that correlation between emerging markets within regions has increased at a faster rate on average than the correlation with the USA suggests that investors might consider diversification across regions rather than across individual countries within regions. This provides an important question for future research. 


\section{Conclusion}

The purpose of this paper was to examine the way in which stock markets in Latin America have varied over time. Prior to the liberalisation of markets in the early 1990s in Latin America, equity markets tended to be more correlated with the world market portfolio than regionally (although this was fairly low). The debt crisis was a period during which Latin American markets seemed to be exposed to the same exogenous shock from interest rate movements in the UK and US. South American countries embarked upon a radical programme of reform throughout the 1990s that continues today. A future extension of this research may be to examine in more detail the theory underlying 'regional integration' in Latin America. In turn, closer economic union may lead to greater dependence within a regional context that may result in greater contagion effects in the event of financial crises. This may explain why the incidence of regional crises seems to be increasing over time.

Received 12 January 2001, Accepted 7 October 2001

\section{References}

Balassa, B. (1982), The Theory of Economic Integration. Greenwood: Westport

Baldwin, R. E. (1997), "The Causes of Regionalism", Centre for Economic Policy Research Discussion Paper: 1599.

Bekaert, G. and Harvey, C. R. (1995), “Time-Varying World Market Integration”, Journal of Finance, 50(2), pp. 403-444.

Cochinard, S. (1995), "L'Evolution du Concept de Coalition en Theorie des Jeux. (The Coalition Concept in Game Theory)", Revue d'Economie Politique, 105(4), pp. 633655.

de la Torre, A. and Kelly, M. R. (1992), Regional Trade Agreements, International Monetary Fund, Occasional Paper, no.93. Washington D.C.

Gamble, A. (1994), The Free Economy and the Strong State: The Politics of Thatcherism. Macmillan: London.

Ghosh, A. (1992), "Market Model Corrected for Generalised Autoregressive Conditional Heteroscedasticity and the Small Firm Effect", Journal of Financial Research, 15(3), pp. 277-283.

Gwynne, R. (1994), "Regional Integration in Latin America: the Revival of a Concept?", pp. 205; in Gibb, R. and W. Michalak, (eds.), Continental Trading Blocs: The Growth of Regionalism in the World Economy. John Wiley \& Sons: New York.

Harvey, C. R. (1995), “The Risk Exposure of Emerging Equity Markets”, The World Bank 
Economic Review, 9(1), pp. 19-50.

International Finance Corporation (1997), "The IFC Indexes: Methodology, Definitions, and Practices", Emerging Markets Data Base. Washington D.C.

Kim, D. C. (1992), "Open Regionalism in the Pacific: A World of Trading Blocs?" American Economic Review, 82(2), pp. 79-83.

Kim, E. H. and Singal, V. (1993), "Opening up of Stock Markets by Emerging Economies: Effect on Portfolio Flows and Volatility of Stock Prices", in Stijin Claessens and Sudarshan Gooptu (eds.), Portfolio Investment in Developing Countries, World Bank Discussion Paper 228, Washington D.C.

Michalak, W. (1994), "The Political Economy of Trading Blocs", in R. Gibb and W. Michalak (eds.), Continental Trading Blocs: The Growth of Regionalism in the World Economy. John Wiley \& Sons: New York

Nofal, M. B. (1995), "The Economic Integration of Argentina and Brazil, MERCOSUR, and the Regionalisation of the Southern Cone Market", in Elsie Echeverri-Carroll (ed.), NAFTA and Trade Liberalisation in the Americas, pp. 203-230. University of Texas: Austin.

Pompili, T. (1994), "Structure and Performance of Less Developed Regions in the EC", Regional Studies, 28(7), pp. 679-693.

Ramchand, L. and Susmel, P. (1998), "Volatility and Cross Correlation across Major Stock Markets", Journal of Empirical Finance, 5(4), pp. 397-416.

Richards, A. J. (1996), "Volatility and Predictability in National Stock Markets: How do Emerging Markets differ?", International Monetary Fund Working Paper, no.29.

Rockinger, M. and Jondeau, E. (2001), "Conditional Dependency of Financial Series: An Application of Copulas", HEC Working Paper.

Tussie, D. (1998), "Globalisation and World Trade: From Multilateralism to Regionalism”, Oxford Development Studies, 26(1), pp. 33-45.

Vernon, R. (1996), "Passing through Regionalism: The Transition to Global Markets", World Economy, 19(6), pp. 621-633.

Young, S., Hood, N. and Peters, E. (1994), "Multinational Enterprises and Regional Economic Development", Regional Studies, 28(7), pp. 657-677. 